\title{
Technical innovations and optimizations for intermediate ice-core drilling operations
}

\author{
Jack TRIEST, ${ }^{1,2}$ Robert MULVANEY, ${ }^{1}$ Olivier ALEMANY ${ }^{2}$ \\ ${ }^{1}$ British Antarctic Survey, Natural Environment Research Council, Cambridge, UK \\ E-mail: jack.triest@lgge.obs.ujf-grenoble.fr \\ ${ }^{2}$ Laboratoire de Glaciologie et Géophysique de l'Environnement (LGGE), Université Grenoble Alpes and \\ Centre National de la Recherche Scientifique (CNRS), Grenoble, France
}

\begin{abstract}
The British Antarctic Survey, in collaboration with Laboratoire de Glaciologie et Géophysique de I'Environnement, has in recent years successfully drilled to bedrock on three remote sites around the Antarctic Peninsula. Based on the experience from the multi-season project at Berkner Island (948 $\mathrm{m}$ depth, 2002-05) we optimized the drill set-up to better suit two subsequent single-season projects at James Ross Island (363 m depth, 2008) and Fletcher Promontory (654 m depth, 2012). The adaptations, as well as the reasons for them, are discussed in detail and include a drill tent set-up without a trench; drilling without a borehole casing with a relatively low fluid column height; and using a shorter drill. These optimizations were aimed at reducing cargo loads and installation time while maintaining good core quality, productivity and a safe working environment. In addition, we introduce a number of innovations, ranging from a new lightweight cable tensioning device and drill-head design to core storage and protection trays. To minimize the environmental impact, all the drill fluid was successfully recovered at both sites and we describe and evaluate this operation.
\end{abstract}

KEYWORDS: ice coring

\section{INTRODUCTION AND MOTIVATION}

Following the successful drilling project at Berkner Island (Mulvaney and others, 2007), our aim was to drill on other sites around the Antarctic Peninsula with a similar set-up. However, logistic constraints dictated that we would only have one season, with little or no pre-deployment, for these projects (Mulvaney and others, 2014). The sites at James Ross Island (JRI) and Fletcher Promontory (Fletcher) were chosen for their scientific significance (Mulvaney and others, 2012; Abram and others, 2013), and bedrock had to be reached to obtain old enough ice for the project to be considered a success.

The limitations of having just one season, minimal crew, and no vehicles apart from a small snow-blower and a skidoo made us evaluate the Berkner project set-up and look for faster and more lightweight set-up methods while maintaining core quality and a safe working environment. We identified that this could be achieved by finding solutions for the following:

no drill trench but a slotted tent roof and shorter drill instead

lightweight floor for single-season use

no borehole casing

new cable spooler

In addition to the above we looked for ways to better protect the core during end-of-season transport and recovery of the drill fluid for reuse and minimal environmental impact.

\section{DRILL TENT SET-UP}

With minimal manpower and no vehicles, it is timeconsuming to create a drill trench deep enough for the mast to be tilted vertically within a standard closed-off tent or
WeatherHaven. To avoid the need for a drill trench, the WeatherHaven was modified by creating a slot in the roof that allows the mast to swing from horizontal to vertical and protrude through the top of the WeatherHaven (Figs 1 and 2). Five standard arched frame sections were modified by shortening the tubes by $\sim 20 \mathrm{~cm}$ and welding a short horizontal section to the top end. This allows the arches to be interconnected with straight tubes, similar to the rest of the construction, to form a slot in the centre of the roof $\sim 40 \mathrm{~cm}$ wide. To increase the length of the slot and build rigidity into the frame, the first and last arches were terminated by $U$-shaped frame sections that in turn connect to the standard central roof section of the frame. To further strengthen the frame, U-bolt clamps are used to bolt down the horizontal frame sections to the arches through small slots, the width of the $U$ bolt, in both ends of the tube.

Figure 1 shows the top end of one of the modified arches and the $U$ bolts in place. Also visible in this photo is a black hook coming through the tent canvas and hooked around the horizontal frame tubes. Four of these hooks are attached to ratchet-straps, which in turn are anchored in the snow on

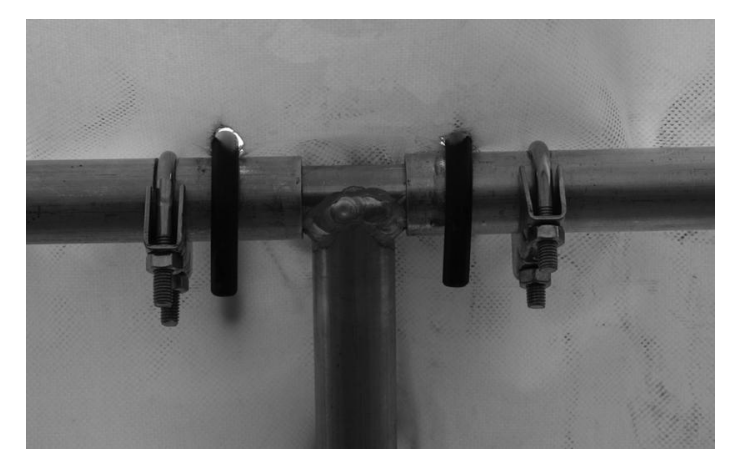

Fig. 1. Modified arch detail. 


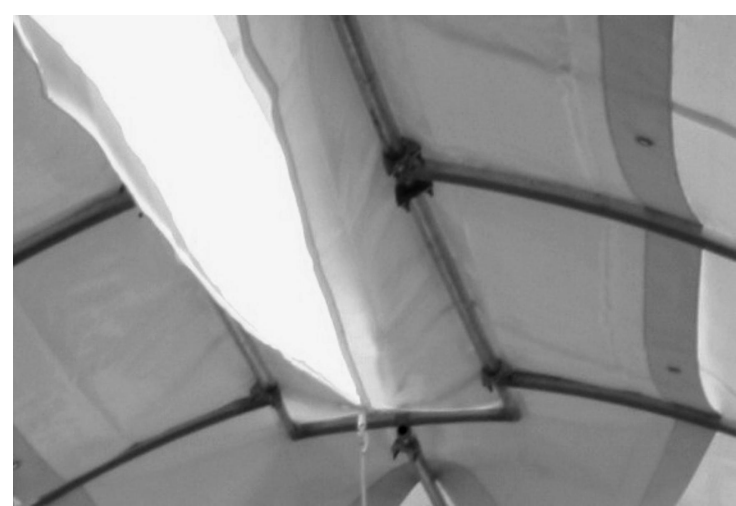

Fig. 2. Roof slot.

the outside of the WeatherHaven, and serve as tensioners to reinforce the frame against side loading from wind or snow.

To keep out the worst of the weather, a custom tarp with a zip was made that can be placed over the slot. Most of the time it proved unnecessary to keep out snowdrift, as the curve of the WeatherHaven makes the snow blow over without entering the tent. However, it proved useful to block out the direct sunlight, which on sunny days could significantly raise the temperature, which in turn is not good for the ice cores and can create meltwater on the drill components. This is probably the main downside of this setup: without a deep trench acting as a cold trap, temperatures can get rather high on sunny days. For several days at JRI the temperature exceeded $0^{\circ} \mathrm{C}$ and we had to alter the shift pattern to avoid the warmest part of the day.

At Berkner Island a multilayer wooden floor was used that had to withstand several winters and multi-season use (Fig. 3). For the single-season projects we considered not using a floor at all, but decided against it as a stable floor is much safer and easier to work on, especially at warmer sites on the Peninsula where the snow in the tent would melt quickly, resulting in an uneven and slippery surface.

A wooden floor was chosen because it is easy to work with and because wood has a variety of uses. Figure 4 shows a detailed drawing of the floor construction. Top quality grade scaffolding planks, to ensure straightness, form the base layer, and orientated strand boards (OSB sheets) are used for the top layer. The floor is made to the exact dimensions of the drawing to ensure that the winch and mast are in the right position in relation to the slot in the WeatherHaven roof. The water-resistant OSB sheets are cheaper, lighter and much less slippery than plywood sheets. The scaffold planks are best laid on a level layer of firn, ideally flattened and prepared

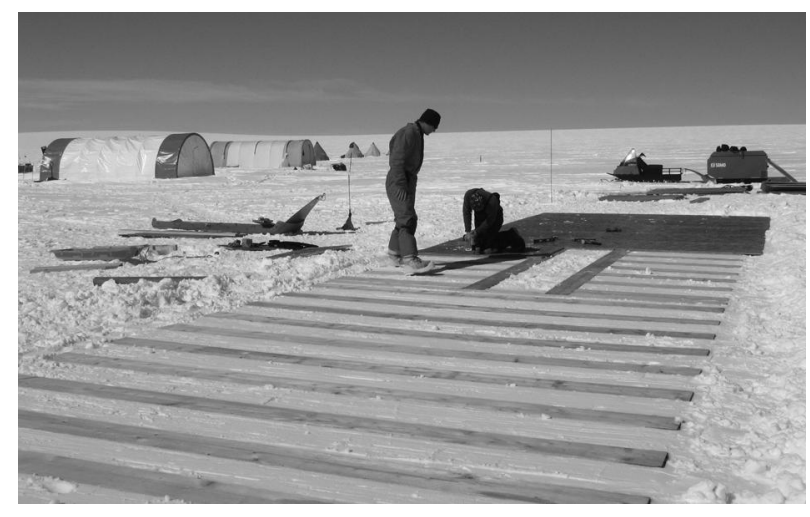

Fig. 4. Floor construction.

with a snow-blower, with the spaces between planks filled in with snow. Cutting and screwing the OSB boards is a quick process and the whole floor can be laid in 1 day, or ideally an afternoon and a morning to allow the snow between the boards to refreeze overnight.

This floor has proven to hold up well for one season. One modification for future projects would be to place the scaffolding boards that are underneath the winch to one side of the slot, edge-on for greater stiffness, as it has been found that the heavy winch will slowly distort and sink the floor into the snow over the course of the season. This in itself is not a real problem, but the slight tilt can cause the mast to misalign with the borehole, tent slot and extraction table, etc.

\section{DRILL LENGTH}

The ambitious target of reaching bedrock in a short single season made us evaluate the various parameters that determine core production and what the impact would be of using a short drill as a result of a set-up without a drill trench. The drill tent set-up as described previously essentially determines the maximum possible drill length because of the way the tent roof slot, drill trench and extraction table add up and need to fit within the $48 \mathrm{ft}$ (14.6 m) WeatherHaven Series 4 tent.

The use of a shorter drill does not significantly impact a project such as JRI because, even at a maximum depth of $\sim 363 \mathrm{~m}$, drill tripping times are relatively short. Use of a longer drill would result in a bigger tent and floor, which would mean a higher total weight of cargo which in turn would require more flights and thus carry a higher risk of not getting cargo in on time and add significantly to the project cost.

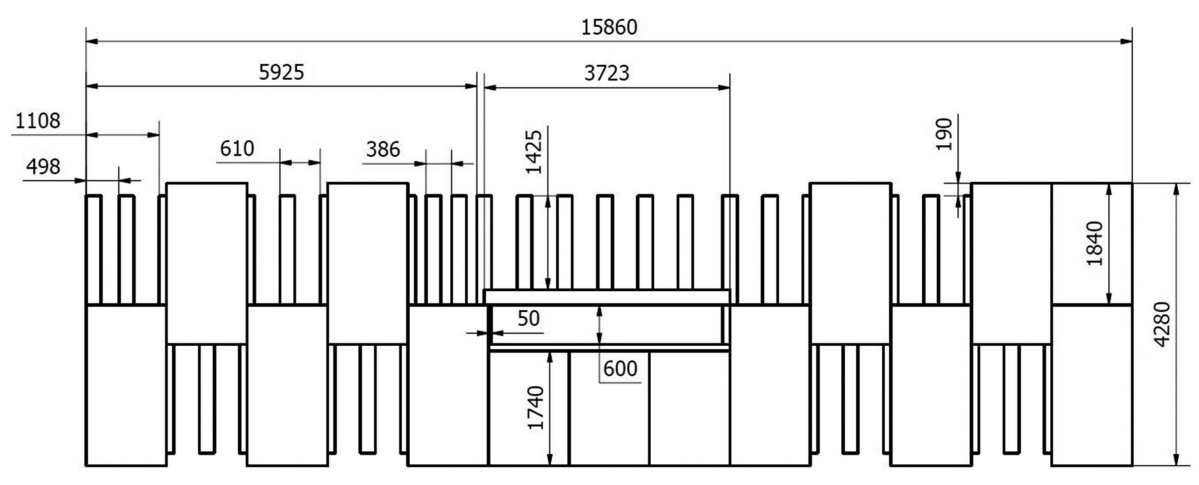

Fig. 3. Floor layout. 


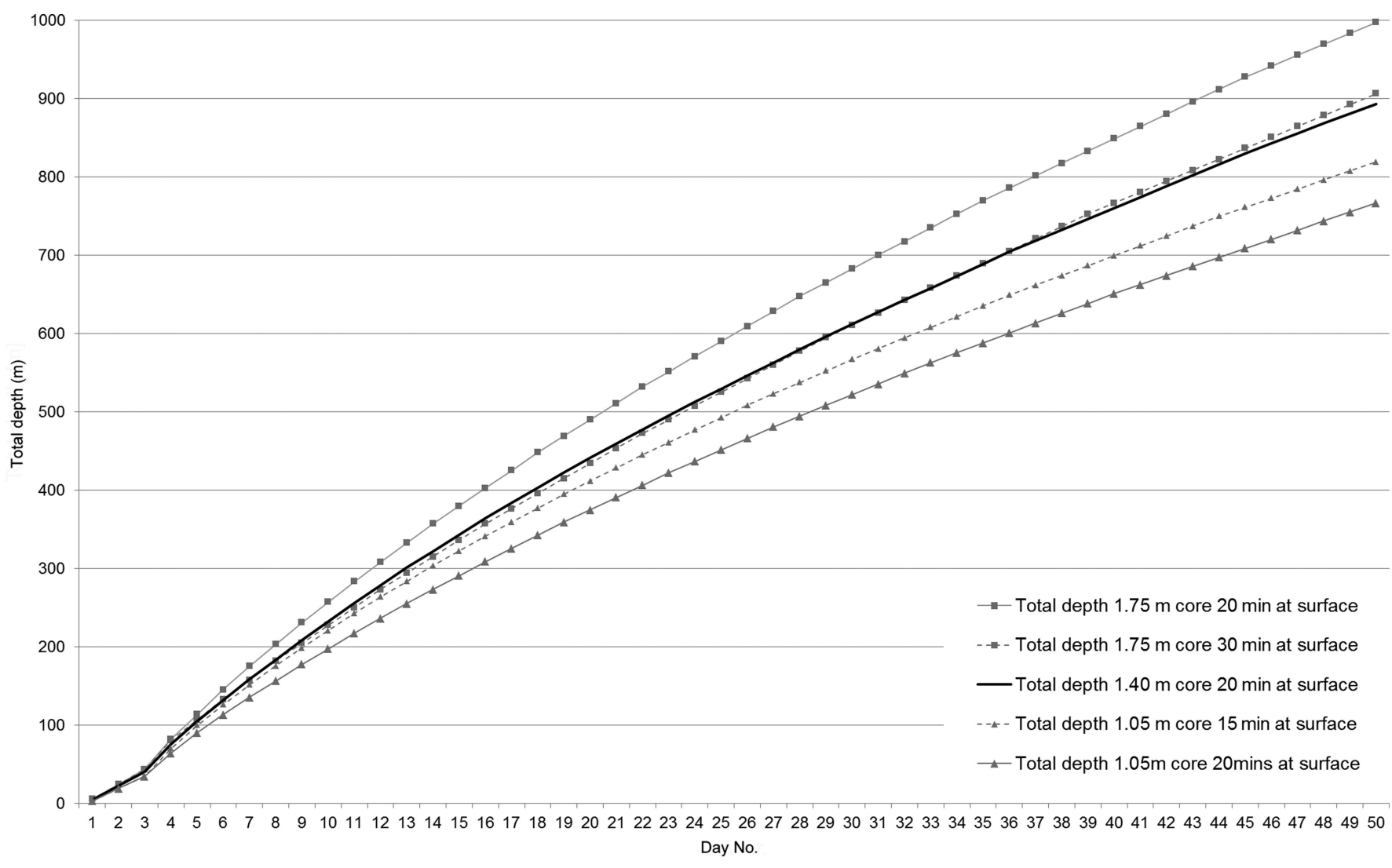

Fig. 5. Production curves.

The data from the JRI and Berkner drill runs allowed a detailed analysis of some key parameters to better estimate and schedule the drilling for Fletcher, where time would be the critical factor. A theoretical production curve, based on these real data, also helps with tracking progress and decision-making while drilling, which proved necessary at Fletcher and is described later. It is of course not possible to account for major unforeseen problems or delays.

Based on a fixed winching speed, drill speed and a surprisingly constant efficiency rate to account for ongoing drill modifications and minor repairs, it is apparent that surface time is one factor that can be evaluated in terms of productivity against core length. Figure 5 shows production curves for these variables.

The first day is assumed to be for drill testing on three cores only. The next two days are training days without working in shifts and assumed to be limited to 15 runs $^{-1}$. From day four, drilling takes place in a shift pattern (four 4 hour shifts) and the theoretical production is calculated from a constant winch speed, drill speed and surface time. An efficiency factor of 0.85 is used to match the curve with the reality based on JRI and Berkner data. This factor proved rather consistent for our projects when averaged over a whole season.

The first three curves in the Figure 5 legend plot the theoretical daily progress for three different average core lengths of 1.05, 1.40 and $1.75 \mathrm{~m}$, while keeping drill speed, winching times and surface time between runs constant. It is obviously beneficial to drill longer cores since, with a $1.75 \mathrm{~m}$ core length, a depth of $600 \mathrm{~m}$ can be reached in 26 days, which would take 30 days with a $1.4 \mathrm{~m}$ average core length and 36 days with a $1.05 \mathrm{~m}$ core length. What is interesting, however, is that when the surface time between runs is increased from $20 \mathrm{~min}$ to $30 \mathrm{~min}$ for the longer
$1.75 \mathrm{~m}$ core, daily progress is equal to using a $1.40 \mathrm{~m}$ core with a 20 min surface time. Or considering the opposite: when using a $1.05 \mathrm{~m}$ average core length with a reduced surface time of $15 \mathrm{~min}$, daily progress is considerably closer to the $1.40 \mathrm{~m}$ core length progression. This illustrates that an optimal balance can be achieved between average core length and surface time between runs.

A drill for a $1.75 \mathrm{~m}$ core length requires a longer chips chamber, which would result in a drill $\sim 1 \mathrm{~m}$ longer than the drill we currently use. This length of drill does not fit within the existing tent set-up and would therefore require a longer tent and more wood for the floor, which all add up to more weight and extra flights. It is difficult to reduce the surface time between runs when running with longer cores, as the core barrel very likely requires extraction with a collar and a winch (rather than pulling by hand) and the pump requires more cleaning and maintenance than a booster. A drill that

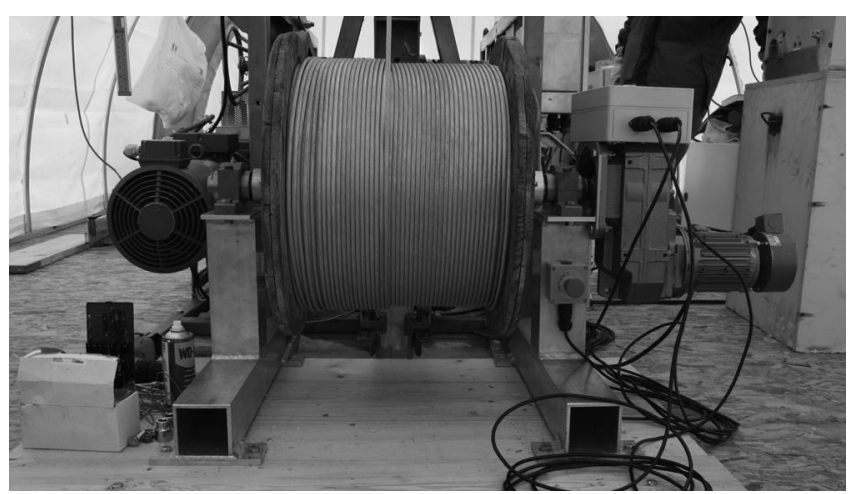

Fig. 6. Cable spooler. 


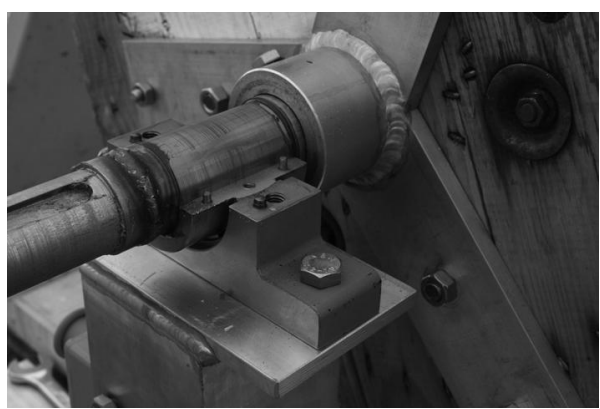

Fig. 7. Split-bearing detail.

produces cores between 1.2 and $1.4 \mathrm{~m}$ most likely works well with a booster (easy cleaning, less dense packing of chips), and the core barrel can easily be extracted by hand without the need for a barrel extraction winch. These are only subtle differences with a longer drill set-up, but, as shown in Figure 5, if the surface time can be reduced by 5 or $10 \mathrm{~min}$ as a result, the actual daily production rate for boreholes down to $600 \mathrm{~m}$ is just as fast as when using a longer drill without the additional weight of a larger infrastructure.

\section{CABLE SPOOLER}

A lightweight cable tensioning device, or 'spooler', was developed to allow efficient spooling of the cable from the transport drum to the winch drum under controlled tension in the field. To suit British Antarctic Survey (BAS) operational logistics, it is necessary to separate the drill cable $(250 \mathrm{~kg})$ from the winch $(370 \mathrm{~kg})$ (Mulvaney and others, 2007). This allows for loading into Twin Otter aircraft, and on-the-ground handling without cranes or vehicles, but requires the cable to be spooled correctly in the field. For trouble-free 'tripping' while drilling, without 'nesting' of the cable, it is important to spool the cable onto the winch drum with a controlled tension equivalent to $60-100 \%$ of the weight on the cable when winching up.

The new cable spooler design replaces alternative options of a 'capstan', which is both heavy and costly, or dragging a skidoo, which affords little to no control and requires the cable to be completely unrolled. The new design (Fig. 6) is built up from two lightweight aluminium frames onto which split slide bearings are mounted. The split bearings allow the drum with removable shaft to be easily dropped onto the lower bearing block (Fig. 7). Once in place, a parallel shaft gear motor (Wattdrive AF range) is pushed onto the drum shaft and bolted to the aluminium frame to transmit the torque. This 'floating' assembly with the hollow shaft of the gearbox helps to prevent misalignment and subsequent friction and bearing overloading.

The tension for spooling the cable is created by a magnetic particle brake (MAGPowr GBA-24V; Fig. 8) which is mounted on the back of the electric motor. A $0-24 \mathrm{~V}$ d.c. voltage controls the braking force and, using the high gearbox ratio, the cable tension can be varied from several newtons up to $1800 \mathrm{~N}$.

The magnetic brake relies on friction so does get warm, but has not been found to overheat during the 1 hour operation to spool a $1 \mathrm{~km}$ cable. In case of demagnetization, the unit is completely field-serviceable or replaceable with a spare unit. Units are low-cost and small $(150 \mathrm{~mm} \times 80 \mathrm{~mm})$. The total weight of the assembly (excluding cable and drum) is $<80 \mathrm{~kg}$.

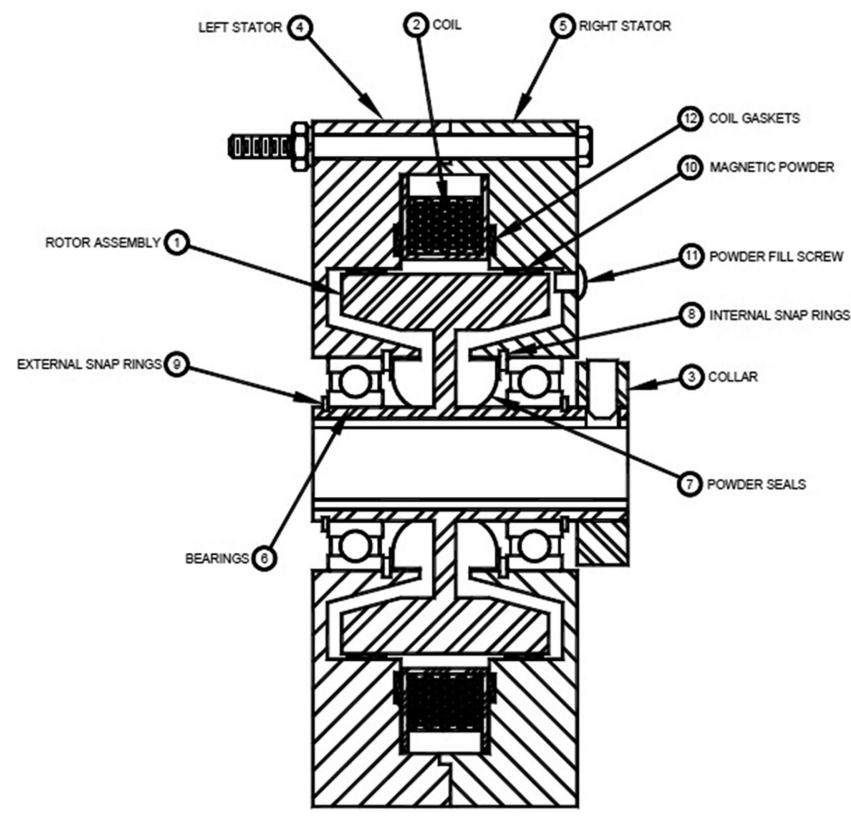

Fig. 8. Magnetic particle break.

An additional benefit of having the motor-gearbox assembly is that the cable can easily be spooled back onto the transport drum at the end of the season.

\section{RUN DETAILS, CORE QUALITY AND DAILY PRODUCTION}

The drill provided by Laboratoire de Glaciologie et Géophysique de I'Environnement (LGGE) through Centre de Carottage et de Forage National ( $\mathrm{C} 2 \mathrm{FN}$ ) for both projects has a total length of $\sim 5 \mathrm{~m}$ and fits well within the constraints of the drill tent set-up. The maximum core length determined by the core barrel is $1.45 \mathrm{~m}$. It was found, however, that at depths greater than $\sim 300 \mathrm{~m}$ the maximum core length is determined by the packing of the chips chamber rather than the length of the core barrel. At lower depths we therefore limited the drill runs to a core length of $1.2 \mathrm{~m}$ to avoid high current and loss of chips at the end of the run. This requires discipline on the part of the drillers as it is tempting to continue drilling up to a full core barrel during a smooth run but loss of chips is very likely to have a negative impact on the next runs.

The average core length when considering all the runs, including those with no core at all, was $1.10 \mathrm{~m}$ for JRI and $1.0 \mathrm{~m}$ for Fletcher. Excluding the 'lost runs' results in an average of $1.15 \mathrm{~m}$ for JRI and $1.05 \mathrm{~m}$ for Fletcher. Figure 9 displays the daily core production for both projects in relation to the theoretical planning described earlier.

It is clear that JRI (dark grey bars and line) was off to a good start, and drilling continued at a very good rate almost consistently above expectation. The one day without production was due to an electrical problem on the winch, which had to be fixed. Despite relatively short cores, production was good due to the previously covered parameter of a short surface time often as low as 7 min between runs. One reason for this was the use of a booster, instead of a pump, which worked very well at JRI. Core quality was consistently very good, with minimal cracks or breaks.

Fletcher progress (black bars and line) was slower from the beginning despite a near-identical set-up to JRI. The 


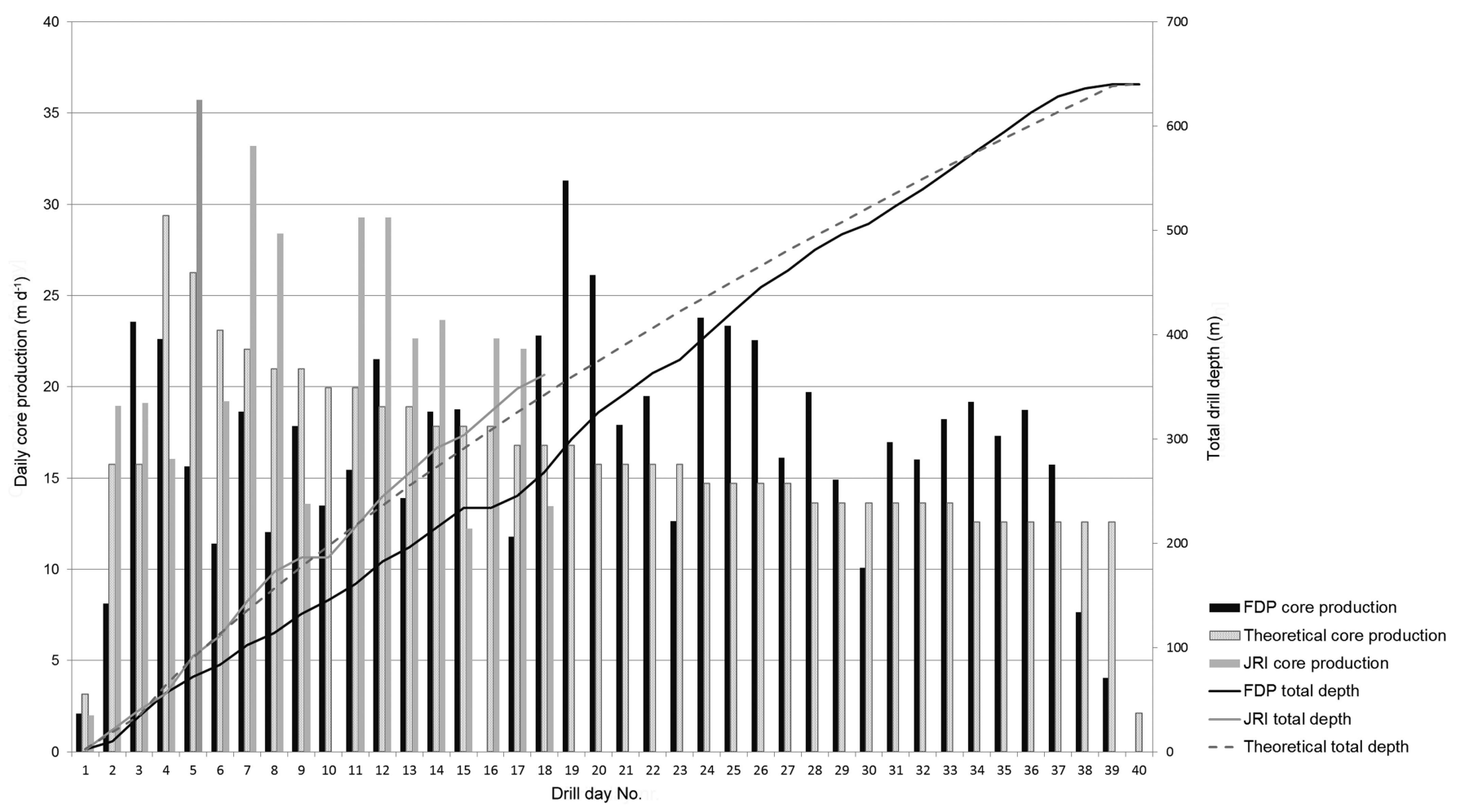

Fig. 9. Daily core production.

booster hardly worked and had to be replaced with a pump as soon as 'wet' drilling started. Modifications to the booster, such as its position and reducing the gap between the barrel and booster flights, showed no marked improvement, and so far no explanation has been found why the booster would not work during this season. Different cutters, anti-torque settings and valve arrangements were tried, but without achieving a satisfactory routine set-up similar to JRI.

The one day without production is a day off for Christmas (25 December). Days with a production around $10 \mathrm{~m} \mathrm{~d}^{-1}$ are half-days off every 7 days. It is clear that by day 16 we were $>75 \mathrm{~m}$ behind schedule, which could have resulted in the drilling taking a week or more longer than planned. The decision was taken to change the shift pattern from $4 \times 4$ hours to $6 \times 4$ hours, which, with seven people in the field, meant three shifts of two people round the clock. With no rest period in camp and the relentless rhythm, it can be hard going and the risk of errors is high, but there was a clear increase in the slope of daily production, and bedrock was eventually reached within the available time.

Core quality at Fletcher varied from good to acceptable through the brittle zone. From $550 \mathrm{~m}$ depth there is a clear increase in core breaks (see Fig. 10), and thin white horizontal cracks were visible on the surface. Ongoing modifications and careful attention to the drill set-up did not avoid this microcracking, which may make certain sections unsuitable for future gas analysis. Despite the cracking and increase in breaks, very few pieces of the core are missing and the cores are not too fragile to handle or process. The core quality through the brittle zone at Fletcher would almost certainly have benefited from a fully balanced fluid column, but since, from the outset, the key objective for this project was to reach the older ice close to bedrock within a single season, we accepted the trade-off of less good-quality brittle ice.

\section{DRILLING WITHOUT CASING AND LOW FLUID COLUMN HEIGHT}

Another relatively time-consuming task for intermediate drilling projects is to install a borehole casing to $80-100 \mathrm{~m}$ depth to close off the porous firn layer. We opted not to install a casing for these projects but to lower a hose into the borehole instead to pump the fluid into the borehole when needed. As there was no need to counteract the borehole closure with a complete fluid column and density-matched fluid (Talalay and others, 2014) we drilled with a low fluid column height of pure Exxon Mobil Exxsol D60 to aid the cutting and chips transport.

The hose used to pump the fluid into the borehole was a $100 \mathrm{~m}$ long layflat PVC hose with a diameter of $1 \frac{1 / 4}{4}$ in $(32 \mathrm{~mm})$. A metal tube attached to the end of the hose provides weight and stiffness for easy lowering into the borehole by hand. To avoid dropping and losing the hose in the hole, it was tied off securely at an adequate length. With the hose down to a depth of $80 \mathrm{~m}$ it is a little awkward to pull it back out, and it is better if heavier types of hose are not raised and lowered by hand like this. Rather than being rolled up between uses, the hose was simply dropped in a large box for storage. This type of hose is cheap, lightweight and takes up minimal space when rolled up for easy transportation. However, the PVC is not fully resistant to the D60 and stiffens at lower temperatures, which together can lead to cracks toward the end of the season. For future projects a similar type of layflat hose but from a more suitable material should be sourced, but its weight should remain the same or less.

For best practice the drill fluid was recovered wherever possible inside the drill trench. The extraction table, mast, winch and inclined trench were installed with drip trays or lined with plastic sheet to collect the fluid. We expected fluid 


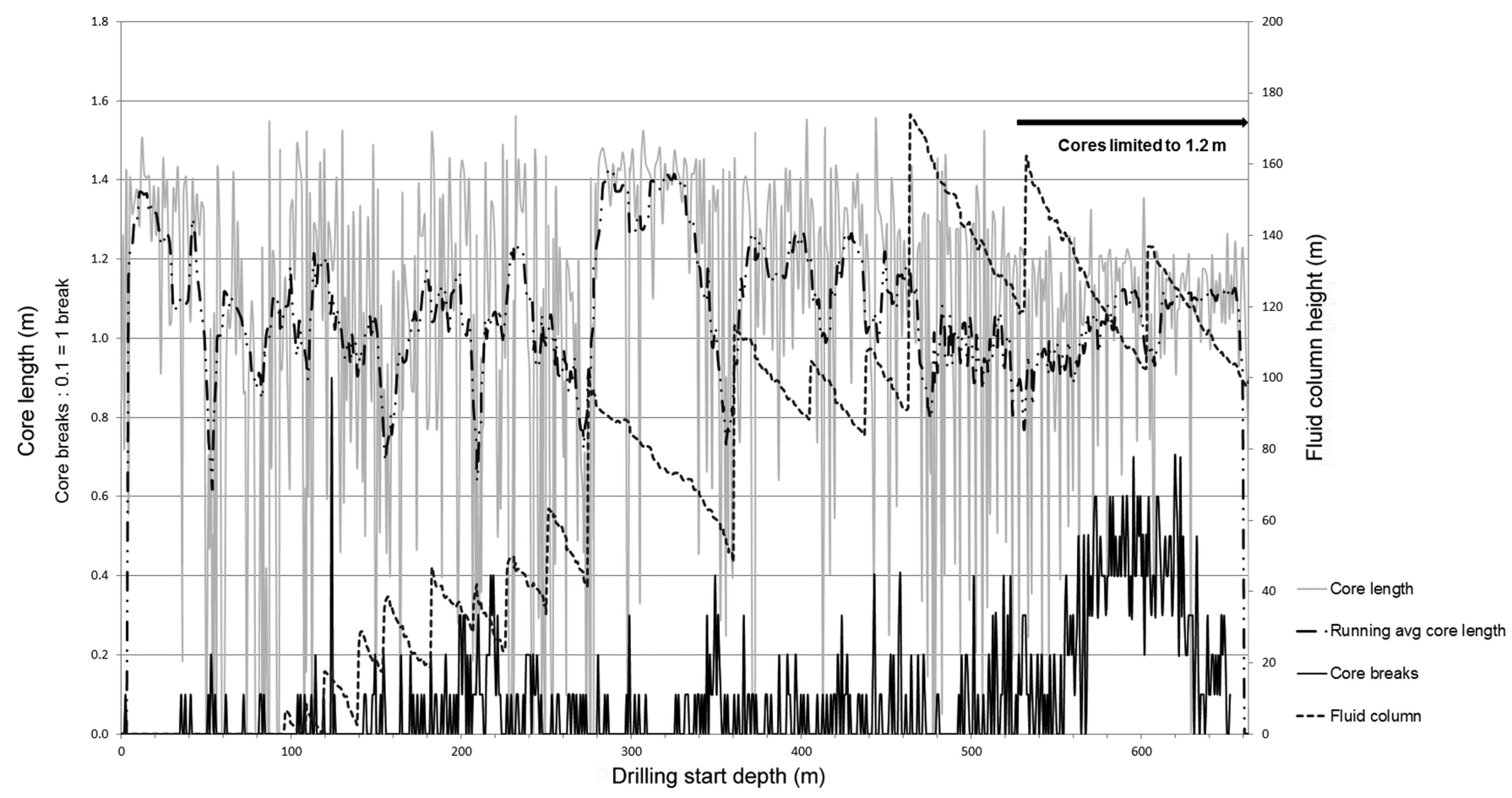

Fig. 10. Core details and fluid column.

losses to be higher by not having a casing, but fluid loss at JRI was about normal for this type of project, with $18 \%$ loss.

At Fletcher the fluid loss was much higher than expected despite a similar set-up. In total, 17 drums (3500 L) of drill fluid were used and only 6 removed from the site, so about 11 drums $(2000 \mathrm{~L})$ were lost $(64 \%)$. About 3 drums can be accounted for as normal losses from minor spillages, absorption into chips, etc. Detailed evaluation of the drill sheet data reveals that most likely much of the remaining fluid loss occurred when filling the borehole. It appears that the hose was not always dropped low enough to be well under close-off depth (which was later found to be $75 \mathrm{~m}$ rather than the predicted $65 \mathrm{~m}$ ) and drill fluid leaked into the firn. Fluid column height gain in relation to the amount of fluid added should be monitored more carefully to avoid this in future projects. The higher fluid loss is a disadvantage, in terms of cost and environmental impact, of not using a casing, and improvements should be considered for future projects. However, this should be evaluated against a significant saving in time and resources when installing a casing, which, in turn, is highly unlikely to be removed.

One key point is whether the lower fluid column height affects core quality and/or drilling performance. At JRI the fluid column height was maintained between 100 and $160 \mathrm{~m}$, and core quality and core production were very good throughout. With a maximum depth of $364 \mathrm{~m}$ and no brittle-ice zone, the possible effects of a reduced fluid column would be limited and not easy to notice.

At Fletcher both the core production and core quality varied. Figure 10 shows the fluid column height vs core length and number of core breaks at Fletcher. Despite numerous 'zero'- and limited-length runs, no obvious relation can be seen between the fluid column height and core production. During drilling, the general impression was that drilling was easier with a higher fluid column, but the plotted data only show a possible link between 280 and $340 \mathrm{~m}$ depth. The average core length (centred running average of 10) drops significantly between 340 and $380 \mathrm{~m}$ when the fluid column becomes lower than $70 \mathrm{~m}$. However, changes were also made to the drill itself at this time, so it is uncertain whether the fluid column height alone is the reason. Lower down, some runs showed white-veined microcracks or a spiral pattern on the outside of the core, and from $550 \mathrm{~m}$ depth onwards there is a clear increase in core breaks due to the brittle zone, but no clear correlation between actual core quality and fluid column height can be found in the data (detailed ice-core log).

On the whole, we found that drilling with a $<100 \mathrm{~m}$ height fluid column was difficult, and core quality was, rather subjectively, less good. A higher fluid column may not affect the actual drill performance, but the resulting increased hydrostatic pressure will better protect the ice core from sudden release in stresses when cutting it, especially at lower depths.

\section{DRILL-HEAD DESIGN MODIFICATIONS}

A new style of drill head has been designed and tested to try to improve core quality and avoid 'lost' runs due to ice build-up under the 'shoe'-mounting screws as found on many of the drill heads currently in use. In addition to mounting the shoes differently, the cutters are machined using a new method which results in a slightly altered cutting geometry.

Figure 11 shows a photo of the new drill head mounted on the BAS shallow drill. To avoid the more usual countersunk hole with screw head at the base, the shoes are manufactured with a short stub that allows them to be fastened from the top through a hole in the drill-head body. Accumulated snow and ice in the mounting screw hole was not found to be a problem and, if necessary, was easily cleared with some alcohol. Twisting of the shoes is limited by making them come up to the back face of the cutter and was not found to be a problem. By keeping a small gap, the 


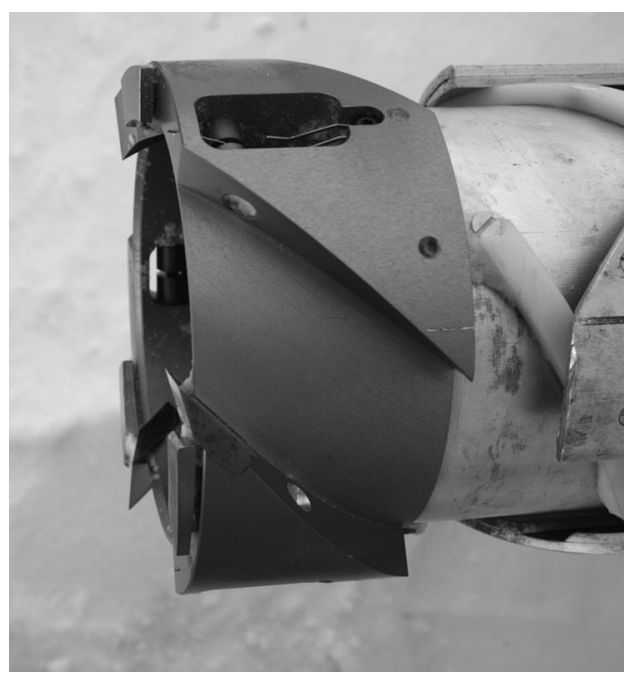

Fig. 11. Drill head.

'pitch' between the cutter edge and the shoe can be accurately set by placing thin washer shims over the shoemounting stub in more or less the conventional way.

The cutters are turned from small rectangular 'blanks' that are mounted at $45^{\circ}$ to the vertical plane on a dedicated jig, positioned the same as when they are mounted in the drill head when finished (Figs 11 and 12). The 'blanks' with the rake angle at $45^{\circ}$ have a cutting angle machined at $30^{\circ}$, resulting in a relief angle of $15^{\circ}$ (Gundestrup and others, 1989). Because the cutters are turned in sets on the jig, this allows for very accurate diameter control and eliminates tolerance problems that can occur when using differently machined (milling and grinding) cutters which tend to have a more complex geometry and are not always consistently ground or used as sets.

The correct geometry, in terms of relief angles, etc., of the cutters, is obtained simply by turning the cutter to a slight taper using the secondary slide on the lathe. The angle of this taper, together with the cutter blank at $45^{\circ}$ to the vertical plane, determines the amount of relief on both the inner and outer radial faces of the cutter. A detailed view of the relief angles obtained in this way can be seen in the dotted circle on the right in Figure 12 'Top view'.

This new design was tested on the BAS shallow drill, as this drill needed a replacement head, and it worked well. Further developments and testing in 'wet' drilling mode are planned for future projects. The design is presented here mainly to share the new manufacturing method and ideas.

This version was made with an M4 threaded hole in the cutter blanks so that they could be fastened with a screw positioned under the shoe and coming through the drillhead body. This mounting with a single hole means that the other faces, but mainly the face that butts up against the slot in the drill-head body, need to be carefully toleranced to ensure accurate positioning and avoid twisting of the cutter when drilling.

A better alternative would be to have a countersunk hole at the top face of the cutter and use a screw through this to fasten it to the turning-jig and drill-head body. This avoids the need for a threaded hole in the cutter, and this, together with the fact that only a single turning or grinding operation is required, means that this type of cutter can easily be made from more difficult-to-machine materials (e.g. tungsten

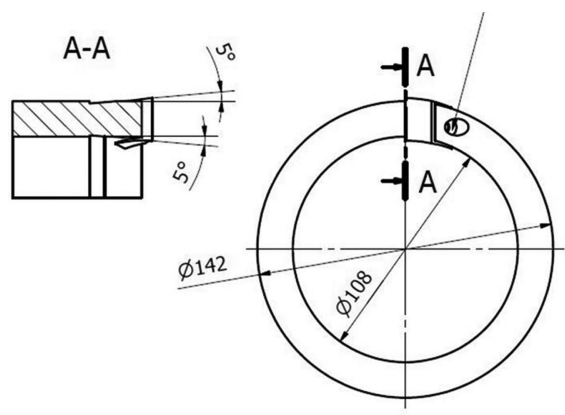

Bottom view

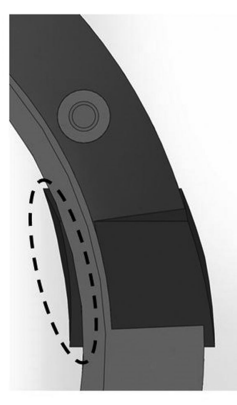

Top view
Fig. 12. Cutter details.

carbide or ceramic) while maintaining high dimensional accuracy by avoiding 'free hand' adjustments and finishing.

This type of cutter is easily produced in larger quantities, which can result in cost savings while maintaining consistent dimensions. Also, recent advances in three-dimensional printing open up the possibility of producing drill-head bodies with good accuracy and more complex shapes in either a polymer or metal. This is especially attractive for low-quantity orders or prototyping new geometries, when conventional machining is not possible or too expensive, and is currently being explored.

\section{ICE-CORE PROTECTION TRAYS}

Complicated logistics can result in much handling of the ice-core boxes, often by people unaware of the fragile contents. To avoid, or greatly reduce in worst cases, ice-core damage during transport, dedicated protection trays were designed and used as shown in Figure 13. They are cut from ultra-high-density polystyrene, making them reusable and recyclable, and bought in sets for about $£ 2$ per set. The split trays allow the core to be completely supported and they stack easily in the core box. As the cores are evenly supported and cannot touch each other, shocks do not propagate through the box, which tend to damage ice cores mostly when cores are packed with bubble wrap or snow. The polystyrene has the additional benefit of thermally isolating the cores well and may prove beneficial in case of freezer failure, negligence, etc. However, the flip side of this is that if the temperature of the cores has risen due to unforeseen circumstances, it may take longer to bring the temperature back down.

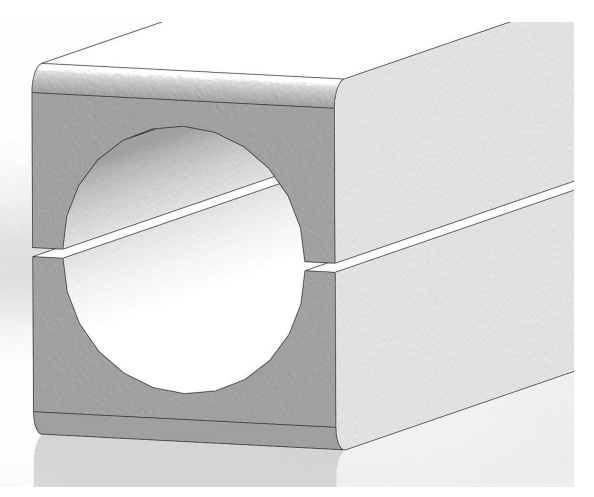

Fig. 13. Core protection trays. 


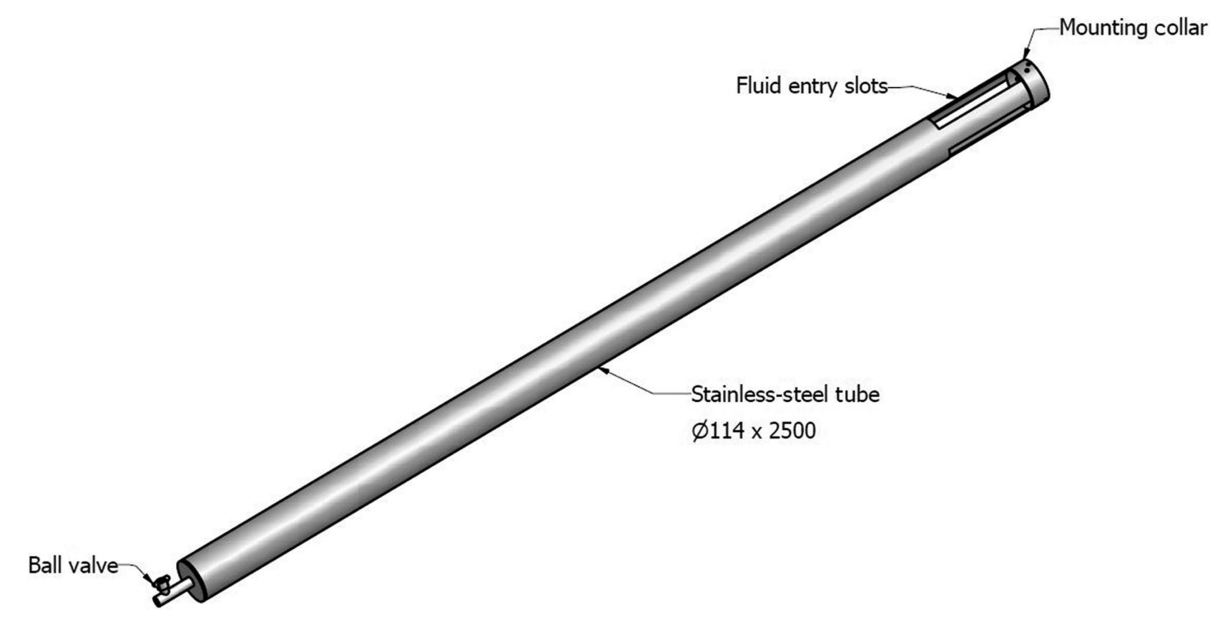

Fig. 14. Fluid-bailing tube. $\phi$ is diameter. Units are $\mathrm{mm}$.

The core boxes are designed to take nine cores of $80 \mathrm{~cm}$ length, and the protection sleeves do not take up more space than the usual bubble wrap or layers of snow. Note the rounded ends for ease of lifting the trays back out of the icecore box. The diameter created by the two sleeves is $\sim 4 \mathrm{~mm}$, larger than the actual ice core, to create space for the plastic layflat bag. They add slightly to the total weight, but this is a price worth paying considering their effectiveness and the efforts required to drill the core.

\section{FLUID RECOVERY}

Aiming for 'best practice' and adherence to the 'Protocol for Environmental Protection to the Antarctic Treaty (1991)', the BAS Environmental Office asked us to find ways to remove the Exxsol D60 drill fluid and plan to leave the drill sites with everything removed since no further visits were planned. Fluid recovery for these two projects was feasible and worthwhile for a variety of reasons, such as intentionally reduced height of fluid column; one-season operation with no borehole closure problem; no interest in revisiting the borehole for further geophysical measurements; and not too deep so tripping times are reasonably short, with maximum 15-20 min one way.

The bailing device (Fig. 14) is an empty tube with large slots at the top for the fluid to easily enter and a ball valve on the bottom flange for easy draining when at the surface. The tube is connected to the winching cable through an eyebolt at the top flange.

The tube has the same diameter as the outer tube of the drill, and the length is determined by the distance between the sheave wheel at the top of the mast and a suitable drum standing on the floor. In our configuration this allows for a tube length of $\sim 2.5 \mathrm{~m}$ with an internal diameter of $100 \mathrm{~mm}$, giving a bailing volume of just over $20 \mathrm{~L}$. The tube should not be made too light; its weight should be more than the displaced fluid mass when entering the fluid to ensure it sinks quickly and avoid coiling and possible kinking of the cable during fast descent. In practice, nearly every bailing run is $100 \%$ effective, so the required number of bailing runs can be easily calculated and planned as shown in Figure 15.

At JRI, ten drums $(2000 \mathrm{~L})$ were removed from the borehole in 3.5 days. A field-improvised syringe system allowed removal of the last $2 \mathrm{~m}$ of fluid column by sucking it into the bailer tube rather than relying on the overflow through the slots at the top of the tube. About six drums (1200 L) of drill fluid were removed from the Fletcher borehole in a similar time of 3.5 days but from a greater depth.

Due to the minimal equipment and manpower needed for bailing, it can be done while packing away the main drill, auxiliary items and processing equipment, etc. Recovery of a $100 \mathrm{~m}$ fluid column, which equates to $\sim 1200 \mathrm{~L}$ (six drums), takes 3 or 4 working days at these intermediate depths with this type of bailer. For boreholes much deeper than $600 \mathrm{~m}$ or fluid columns that are much more than $100 \mathrm{~m}$ high, bailing of the fluid can require more time and fuel, and should be planned in and evaluated accordingly. Fluid recovery should, as far as possible, be done with the available drilling equipment to avoid additional pollution from extra transport, etc. It would not be realistic to expect additional large equipment to be brought to the site for this type of project. The fluid recovery operation could easily be reduced in time by enlarging the volume of the bailer by using a longer tube.

The fluid recovered from JRI was reused at Fletcher and did not seem to cause any problems. After recovery from JRI it was stored in the original drums for 3 years and no alteration or degradation was noticeable. The fluid recovered from Fletcher is currently stored at Sky Blu and is planned to be reused in the coming years at a similar site.

Questions have been raised about the overall environmental cost of the fluid recovery in the light of the extra fuel use for the generator and the flights required to take the fuel back out. We considered this well worthwhile as the fluid on these isolated sites is local pollution, whereas the few extra flights are minimal in the bigger picture. As a community, in collaboration with environmental offices, we should address these questions and ideally develop a guide for decision-making on whether the fluid recovery is worthwhile or not for a given project. With rising costs of the drill fluids and more environmental awareness, fluid recovery will be higher on the agenda in years to come, and a complete, weighted parameter evaluation system will be indispensable.

\section{CONCLUSION}

The optimized set-up for single-season intermediate drilling using BAS logistics has proven to work well. The wooden 


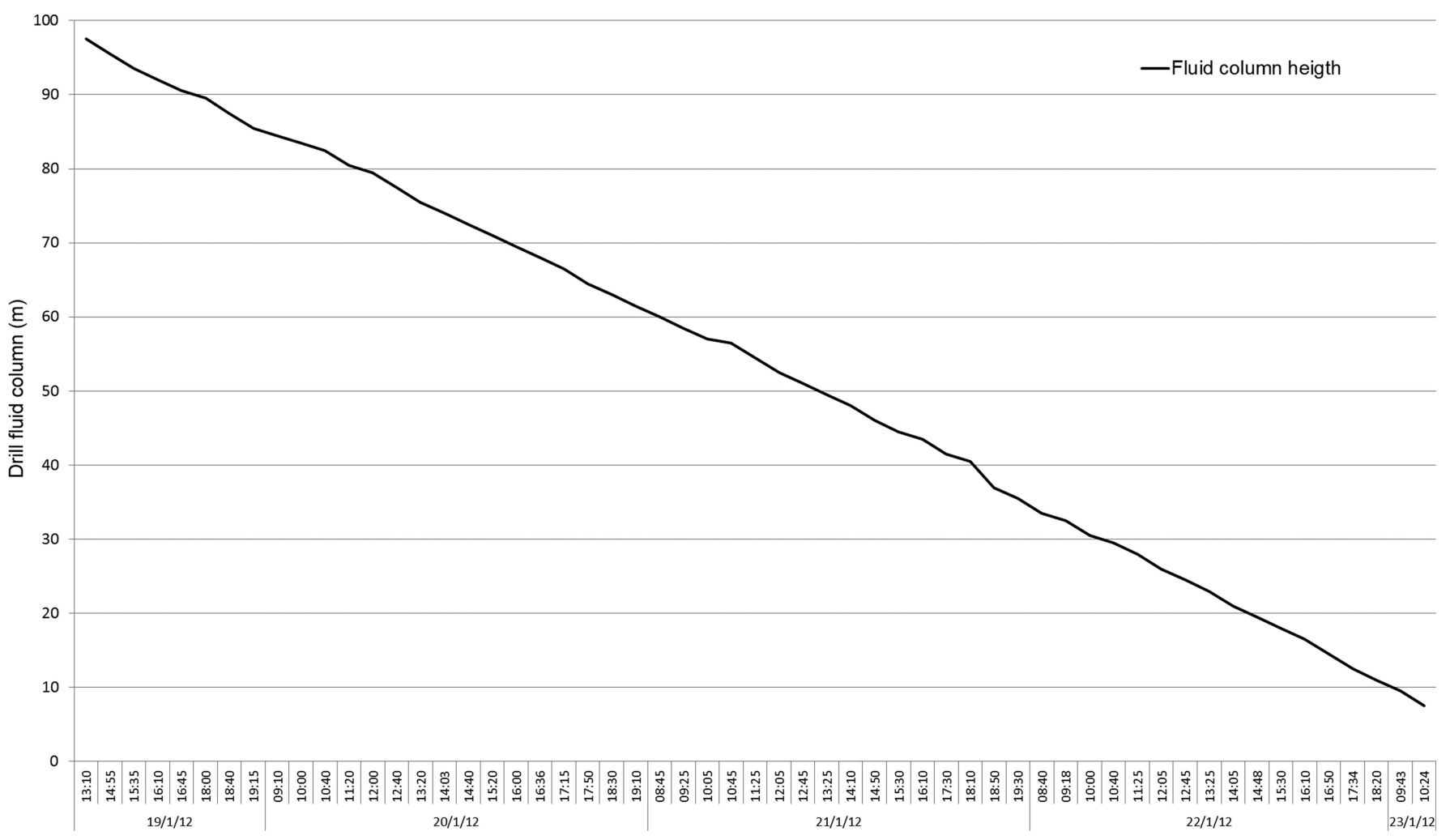

Bailing run timings

Fig. 15. Fluid run times. Dates are day/month/year.

floor, together with the modified WeatherHaven, allows drilling to take place directly from the surface without the need for a deep trench, can be set up in a few days and hold ups well throughout the season. The main downside of drilling without a trench is the possibly higher temperature inside the drill tent at relatively warm sites, especially on sunny days.

Not installing a borehole casing saves a lot of time, and the fluid can easily be pumped in through a long hose that is securely lowered when needed, though fluid loss in the firn can be considerably higher. Drilling with a low fluid column height worked very well at JRI (363 m depth) but has possibly been a negating factor at Fletcher $(654 \mathrm{~m})$ in terms of drilling efficiency and some microcracking in the ice core. There is a trade-off between reaching the objective of older ice close to bedrock in a single season with minimal environmental impact and acceptable core quality in certain sections, as a result of the reduced hydrostatic pressure of the lower fluid column.

The new cable spooler has proven to be very effective with minimal weight and set-up time and can easily be developed for longer cables and higher tensions if required. The new drill-head and cutter design proved to have potential and will be further developed and tested. Simple cost-effective polystyrene core trays are significantly better at protecting cores during transport, weigh less than ice or snow 'packing' and add only marginally to the total weight when compared with bubble wrap.

Recovery of all the drill fluid from the boreholes can be considered 'a first' and resulted in minimal environmental impact on these remote sites. The technologies, cost savings and environmental benefits of fluid recovery for future projects should be evaluated and addressed by the community.

\section{ACKNOWLEDGEMENTS}

We are grateful to the our colleagues in the field: Nerilie Abram, Susan Foord (deceased), Samantha Shelly, Louise Sime (JRI); Emily Capron, Romain Duphil, Louise Fleet, Emily Ludlow, Steve Stout (Fletcher). HMS Endurance provided logistical support for the James Ross project, and we are grateful to the Captain, the Flight Team and the ship's crew for their willingness and enthusiasm to support scientific endeavour. As ever, the BAS Operations and Logistics support from the Air Unit and all on station at Rothera were critical to our success. The two drilling projects were part of the BAS Polar Science for Planet Earth Programme and were funded by the UK Natural Environment Research Council. Support from the Institut National des Sciences de I'Univers, France (INSU/PNEDC 'AMANCAY' project), facilitated by Jérôme Chappellaz and Françoise Vimeux, enabled the technical contribution of the French Drilling and Coring Facility (C2FN - Ice).

\section{REFERENCES}

Abram NJ and 8 others (2013) Acceleration of snow melt in an Antarctic Peninsula ice core during the twentieth century. Nature Geosci., 6(4), 404-411 (doi: 10.1038/ngeo1787)

Gundestrup NS, Hansen SB and Johnsen SJ (1989) Refinements of the UCPH shallow drill. In Rado C and Beaudoing D eds Ice Core Drilling. Proceedings of the 3rd International Workshop on Ice Drilling Technology, 10-14 October 1988, Grenoble, France. 
Laboratoire de Glaciologie et Géophysique de l'Environnement, Centre National de la Recherche Scientifique, Grenoble, 6-13 Mulvaney R, Alemany O and Possenti P (2007) The Berkner Island (Antarctica) ice-core drilling project. Ann. Glaciol., 47, 115-124 (doi: 10.3189/172756407786857758)

Mulvaney R and 8 others (2012) Recent Antarctic Peninsula warming relative to Holocene climate and ice-shelf history. Nature, 489(7414), 141-144 (doi: 10.1038/nature11391)
Mulvaney R, Triest J and Alemany O (2014) The James Ross Island and the Fletcher Promontory ice-core drilling projects. Ann. Glaciol., 55(68) (doi: 10.3189/2014AoG68A044) (see paper in this issue)

Talalay P and 6 others (2014) Drilling fluid technology in ice sheets: hydrostatic pressure and borehole closure considerations. Cold Reg. Sci. Technol., 98, 47-54 (doi: 10.1016/j. coldregions.2013.10.012) 